J. Lake Sci.(湖泊科学) ,2008, 20(1): 88-92

http://www.jlakes.org. E-mail: jlakes@niglas.ac.cn

(C2008 by Journal of Lake Sciences

\title{
人类活动影响下的固城湖环境变迁*
}

\author{
姚书春，薛 滨，王小林 \\ (中国科学院南京地理与湖泊研究所, 南京 210008)
}

摘 要: 2005 年在江苏固城湖湖心采集了连续岩芯, 进行了多环境代用指标(有机碳、氮、磷以及金属元素)的分析. ${ }^{210} \mathrm{~Pb} \mathrm{CRS}$ 模式计算表明, 1980s后沉积速率平均约 $0.067 \mathrm{~cm} / \mathrm{a}$, 与 ${ }^{137} \mathrm{Cs} 1986$ 年时标得到的沉积速率吻合. 而 $1920 \mathrm{~s}$ 至 $1980 \mathrm{~s}$, 固城湖沉积速 率变化较大, 在 $0.056-0.167 \mathrm{~cm} / \mathrm{a}$ 之间, 其中1960s沉积速率最高, 对应于该阶段固城湖强烈的人类围旺活动. 元素 $\mathrm{Cu} 、 \mathrm{~Pb} 、 \mathrm{Zn} 、$ $\mathrm{Cr}$ 的含量在表层增长迅速, 对比参考元素的变化, 表明固城湖受到了一定程度的人为造成的重金属污染. 岩芯 $0.5 \mathrm{~m}$ 到 $1.78 \mathrm{~m}$ 深 度的 AMS ${ }^{14} \mathrm{C}$ 的树轮校正年龄在 $8000-6500 \mathrm{BC}$ 之间, 光释光数据表明同等深度其绝对年龄在7-8ka之间, 多环境代用指标在岩 芯 $30 \mathrm{~cm}$ 深度左右出现了大的转折, 表明近代存在沉积物缺失的可能, 这也许与该区春秋末期以来的反复围层活动有关, 人类 活动改变了湖泊沉积的模式. 有资料表明, 固城湖彻底与太湖隔绝是在公元 1556 年胥溪河河段下坝建成之后. 若依此时间对 应于岩芯 $30 \mathrm{~cm}$ 深度, 得到的平均沉积速率为 $0.067 \mathrm{~cm} / \mathrm{a}$, 与 $1980 \mathrm{~s}$ 以来的沉积速率一致, 有可能指示固城湖至下坝建成以来才 出现沉积物的持续沉积.

关键词: 固城湖; 围层; ${ }^{210} \mathrm{~Pb}$; 沉积物

\section{Environment changes influenced by human activities at Lake Gucheng}

\author{
YAO Shuchun, XUE Bin \& WANG Xiaolin
}

(Nanjing Institute of Geography and Limnology, Chinese Academy of Sciences, Nanjing 210008, P.R.China)

Abstract: Sedimentary cores were taken from the center part of Lake Gucheng, Jiangsu in 2005. The total organic carbon, total nitrogen, phosphorus, metals were analyzed. Calculations of sedimentation rates were achieved using ${ }^{210} \mathrm{~Pb}$ CRS method. The results demonstrated that average sedimentation was $0.067 \mathrm{~cm} / \mathrm{a}$ after $1980 \mathrm{~s}$ corresponding to that from Chernobyl accident marker occurred at 1986 . During the period of $1920 \mathrm{~s}$ and $1980 \mathrm{~s}$, the sedimentation rates varied between 0.056 and $0.167 \mathrm{~cm} / \mathrm{a}$. The high sedimentation rates found in 1960s may be associated with the intense reclamation since 1960s. $\mathrm{Cu}, \mathrm{Pb}, \mathrm{Zn}, \mathrm{Cr}$ showed up-core increase in the top $30 \mathrm{~cm}$ sediment. Combined with the ratio of these elements to Ti it was concluded that the origin of $\mathrm{Cu}, \mathrm{Pb}, \mathrm{Zn}, \mathrm{Cr}$ was not wholly from natural processes. The age was between $6500-8000 \mathrm{a} \mathrm{BC}$ based on AMS ${ }^{14} \mathrm{C}$ results from depth $0.5 \mathrm{~m}$ to $1.78 \mathrm{~m}$, which was comparable with OSL age of 7-8 ka from the same depth. Sharp transition of index including TOC, TN and metals emerged at depth of $0.3 \mathrm{~m}$ may indicate that sediments could be eliminated due to erosion or human impact such as cultivation. It was reported that Lake Gucheng was isolated from Lake Taihu due to establishment of Xiaba at 1556 A.D. Taken the depth of $30 \mathrm{~cm}$ as the time when Xiaba was established, the average sedimentation rate was calculated to be $0.067 \mathrm{~cm} / \mathrm{a}$ which was in agreement with the results of ${ }^{210} \mathrm{~Pb}$ and ${ }^{137} \mathrm{Cs}$ method. Therefore, continual deposition may occur after the isolation of Lake Gucheng from Lake Taihu .

Keywords: Lake Gucheng; reclamation; ${ }^{210} \mathrm{~Pb}$; sediment

湖泊沉积的形成过程是湖泊物理、生物和化学诸过程的综合结果, 因此湖泊沉积物真实地记录了湖 泊过去气候、环境变迁信息. 同时湖泊又与人类活动密切相关, 湖泊周边流域人类活动的信息也无疑保存 在沉积物中. 通过湖泊沉积物中赋存物质的研究, 可以提取自然变化和人类活动的综合信息, 进而可以

* 国家自然科学基金项目(40472085、40771197)和江苏省自然科学基金项目(BK2007534)联合资助. 2006-12-25 收稿; 2007-10-22 收修改稿. 姚书春, 男, 1975 年生,博士; E-mail: shchyao@niglas.ac.cn. 
剖析人类活动对湖泊及其流域环境的影响程度 ${ }^{[-5]}$. 固城湖历史悠久, 受人类活动影响较大, 历史上就曾 有过由于人类修建运河而造成流域水系改变的事件, 围垦活动自春秋时期以来就发生 ${ }^{[6]}$. 本文通过固城 湖沉积物剖面中的碳氮磷、金属元素等指标分析，探讨历史时期固城湖环境演化以及人类活动在湖泊沉 积中的响应

\section{1 固城湖流域概况}

固城湖 $\left(31^{\circ} 14^{\prime}-31^{\circ} 18^{\prime} \mathrm{N}, 118^{\circ} 53^{\prime}-118^{\circ} 57^{\prime} \mathrm{E}\right.$ )位于江苏省高淳县境内, 湖的南部与安徽宣城县接壤(图 1). 目前湖泊面积 $24.5 \mathrm{~km}^{2}$, 平均水深 $1.56 \mathrm{~m}$, 蓄水量 $0.38 \times 10^{8} \mathrm{~m}^{3}$. 湖区属北亚热带季风气候, 年均降水量 $1105.1 \mathrm{~mm}$, 蒸发量 $940.7 \mathrm{~mm}$, 年均温度 $15.5^{\circ} \mathrm{C}^{[7]}$. 固城湖长期以来是湖区人民灌溉、养殖、航运的重要场 所，湖泊的自然环境对湖区人民的生活和经济发展起着重要的作用. 同时，自古以来人类活动也强烈的 改造着湖区的环境和生态条件, 例如围湖造田使湖区面积不断缩小. 历史时期固城湖曾发生多次围湖唇 殖活动，最早开始于春秋末期(公元前 517-416 年)相国圩的建立，后依次经历了北宋、南宋、明代等几个 大的围厓时期. 各历史时期固城湖的演化速度有所不同, 尤以宋时变化最大. 1949 年后, 固城湖经过多次 围剭, 1960 年湖泊面积为 $65 \mathrm{~km}^{2}$, 而 1980 年缩小到 $24.5 \mathrm{~km}^{2}$ ，尚不足其原面积 $221 \mathrm{~km}^{2}$ 的 $1 / 9$.

固城湖原来是属于水阳江、青七江水系, 湖水流人长江, 水量主要发源于皖南山区，长江高水位时部 分水量可倒灌人湖. 公元前 514 年周敬王为开通芜湖到太湖的航道, 以避开长江天险, 在原胥溪河的基础上 开丵今东坝一带的岗丘, 使得固城湖与太湖相通, 又因固城湖水位高于太湖 $4 \mathrm{~m}$ 左右, 所以, 胥溪河开丵 后湖水大量东泄人太湖, 湖面因之剧烈缩 小, 固城湖也因此转变为太湖水系. 后为 控制湖水东流之势，嘉庆三十五年(公元 1556 年)在上坝东 10 里加筑下坝. 因上、 下两坝皆位于高淳县东, 总称东坝, 完全 隔绝固城湖东泄之路, 固城湖也就重归水 阳江、青七江水系. 水系的变化造成其部 分出人湖河流的改变, 如原来固城湖是通 过胥溪河向东流人太湖，现在是通过官溪 河向西流人长江. 同时, 固城湖水位迅速 回升, 湖面扩大. 原在东坝未建前大量兴 建的湖底圩田, 顿成泽国 ${ }^{[6]}$. 据《高淳县 志》记载, “滨湖圩田半为蛟龙之宅, 浸淹 良田四十万余亩”。

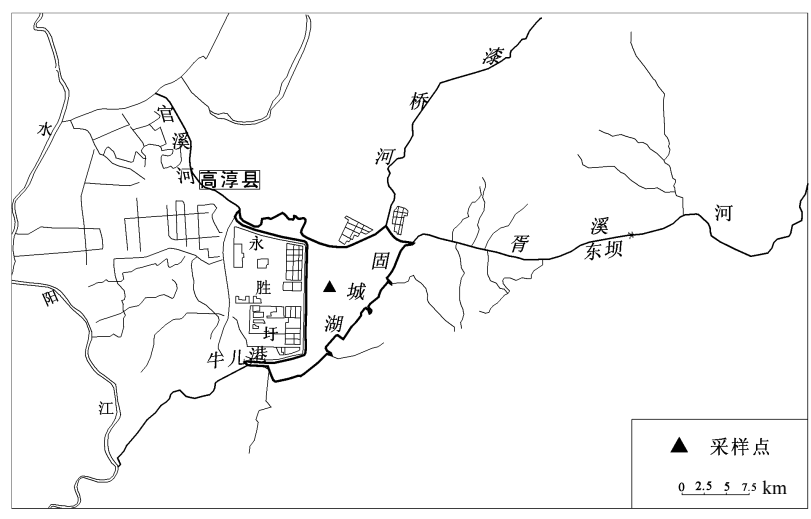

图 1 固城湖地理位置及钻孔

Fig.1 Location of Lake Gucheng and GC core

\section{2 材料与方法}

\section{1 采样}

2005 年 4 月在固城湖原湖心处 $\left(31^{\circ} 17^{\prime} 48.0^{\prime \prime} \mathrm{N}, 118^{\circ} 54^{\prime} 07.2^{\prime \prime} \mathrm{E}\right)$ 用奥地利产水上平台采得三管长岩芯柱 (GC-2, GC-3, GC-4), 其中 GC-3 岩芯长为 $1.78 \mathrm{~m}$, 上部 0-30 cm 为青灰色粉砂质粘土, $26 \mathrm{~cm}$ 处发现结核; $30-60 \mathrm{~cm}$ 为青灰色至灰褐色粘土的过渡段； $60-100 \mathrm{~cm}$ 为灰褐色粘土; $100-130 \mathrm{~cm}$ 为向青灰色粘土过渡; $130 \mathrm{~cm}$ 至底部为青灰色粘土. 用重力采样器在附近采得长为 $32 \mathrm{~cm}$ 的短岩芯柱用于现代沉积物测年 $\left({ }^{210} \mathrm{~Pb},{ }^{137} \mathrm{Cs}\right)$. 短岩芯在野外按 $0.5 \mathrm{~cm}$ 间距分样, 自上而下连续编号, 放人塑料盒中, 密封保存, 带回实验 室后置于冰箱中于 $4^{\circ} \mathrm{C}$ 冷藏以备分析测试.

\section{$2.2{ }^{210} \mathrm{~Pb},{ }^{137} \mathrm{Cs}$, AMS ${ }^{14} \mathrm{C}$, 光释光(OSL)}

样品低温烘干研磨过 100 目篣后, 用美国 EG\&GOrtec 公司生产的由高纯锗井型探测器(Ortec HP GeGWL) 与 Ortec919 型谱控制器和微机构成的多道分析系统进行 ${ }^{210} \mathrm{~Pb},{ }^{137} \mathrm{Cs}$ 测量. AMS ${ }^{14} \mathrm{C}$ 和 OSL 分析 方法见文献[8]. 


\section{3 元素}

沉积物总氮(TN)用重铬酸钾一硫酸消化凯氏法测定，总磷(TP)用高氯酸一硫酸酸溶锄锑抗比色法分 析, 总有机碳(TOC)用重铬酸钾容量法(外加热法)分析 ${ }^{[9-10]}$. 金属元素采用美国产 Leeman Labs Profile 多 道电感耦合等离子体原子发射光谱仪(ICP-AES)测定.

\section{3 结果}

\section{1 年代}

固城湖 ${ }^{137} \mathrm{Cs}$ 整个剖面中只出现了一个峰(图 2), 可能与 1986 年前苏联切尔诺贝利核电站核泄漏有关. 利用此蓄积峰值出现位置作为计年时标, 获得该岩芯 $1.25 \mathrm{~cm}$ 以上沉积速率为 $0.066 \mathrm{~cm} / \mathrm{a}$. 研究发现 ${ }^{210} \mathrm{~Pb}_{\mathrm{ex}}$ 比活度随深度并不呈指数衰减, 这表明沉积物沉积速率可能随时间发生变化. 从 ${ }^{210} \mathrm{~Pb}$ 测年的 CRS 模式计 算出的沉积速率来看(图 3), 固城湖沉积速率变化较大，在 $0.056-0.167 \mathrm{~cm} / \mathrm{a}$ 之间，在 20 世纪 60 年代固城
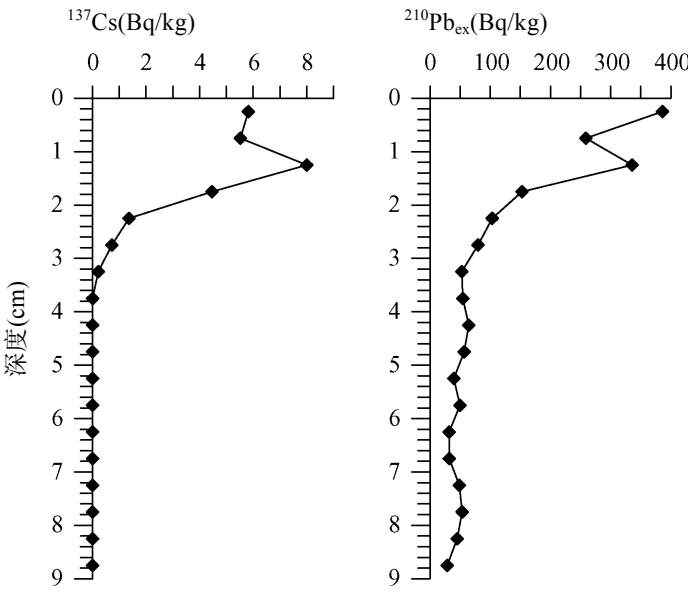

图 2 固城湖沉积物中 ${ }^{137} \mathrm{Cs} 、{ }^{210} \mathrm{~Pb}_{\mathrm{ex}}$ 垂直剖面 Fig.2 The vertical profiles of ${ }^{137} \mathrm{Cs},{ }^{210} \mathrm{~Pb}$ in Lake Gucheng

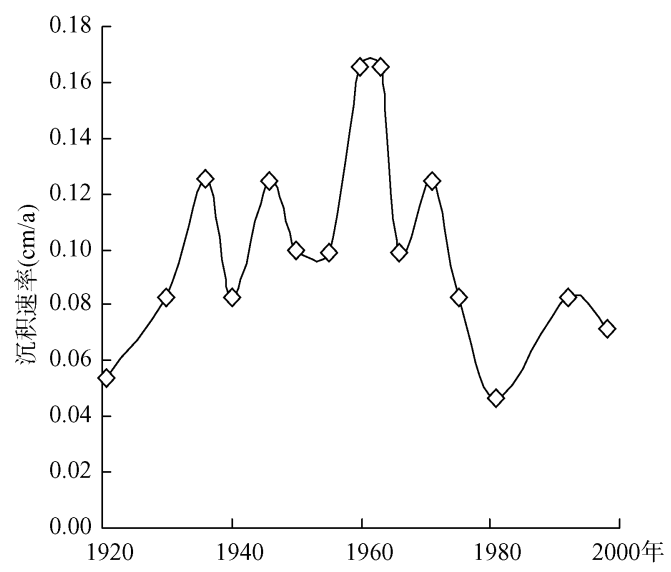

图3 固城湖近代沉积速率变化

Fig. 3 Change of recent sedimentation rate in Lake Gucheng 湖沉积速率最大，也是湖区堆积速率的最高时间 段 ${ }^{[11]}$.

对固城湖岩芯 $\mathrm{AMS}{ }^{14} \mathrm{C}$ 测年结果表明, ${ }^{14} \mathrm{C}$ 年 代约处于 8.8-7.6kaBP 之间，经过校正的 ${ }^{14} \mathrm{C}$ 年代 处于 6.5-8.0 BC 之间，从岩芯上部 $0.5 \mathrm{~m}$ 处到最底 部 $1.78 \mathrm{~m}$ 处的四个样品, ${ }^{14} \mathrm{C}$ 年龄值没有增大, 反而 最底部样品年龄值最小, 总体上, 这些 ${ }^{14} \mathrm{C}$ 年龄值与 地层层序也不一致. $72 \mathrm{~cm}(7.1 \pm 0.7 \mathrm{ka}), 98 \mathrm{~cm}(6.7 \pm$ $0.6 \mathrm{ka}), 123 \mathrm{~cm}(7.1 \pm 0.7 \mathrm{ka})$ 处三个样品的光释光年 龄在误差范围内是一致的，它们没有反映出与地 层层序相同的年龄顺序.

\section{2 沉积物中的元素变化}

固城湖 4 种常量元素 $\mathrm{Ca} 、 \mathrm{~K} 、 \mathrm{Mg} 、 \mathrm{Na}$ 含量 随深度变化的曲线(图 4). 在 $30-25 \mathrm{~cm}$ 深度, $\mathrm{Ca}$ 、 $\mathrm{K} 、 \mathrm{Mg} 、 \mathrm{Na}$ 呈现快速变化的特征. 在 $30 \mathrm{~cm}$ 至钻 孔底部, $\mathrm{K} 、 \mathrm{Mg} 、 \mathrm{Na}$ 含量显示出虽有波动, 但总 体呈稳定的态势. $25 \mathrm{~cm}$ 至钻孔顶部, $\mathrm{Ca} 、 \mathrm{Mg}$ 保持 稳定, $\mathrm{K}$ 轻微增加, $\mathrm{Na}$ 则随着深度减少而减少,

固城湖 4 种重金属元素 $\mathrm{Pb} 、 \mathrm{Cu} 、 \mathrm{Cr} 、 \mathrm{Zn}$ 含 量随深度变化的曲线(图 4). 与 $\mathrm{Ca} 、 \mathrm{~K} 、 \mathrm{Mg} 、 \mathrm{Na}$ 类似，在 $30-25 \mathrm{~cm}$ 深度 $\mathrm{Cu}, \mathrm{Cr}, \mathrm{Zn}$ 含量也呈现快 速变化的特征. 在 $25-0 \mathrm{~cm}, \mathrm{~Pb} 、 \mathrm{Cu} 、 \mathrm{Cr} 、 \mathrm{Zn}$ 总 体上呈现增加的趋势，但 25-14cm 段保持相对稳 定. 底部 $-30 \mathrm{~cm}, \mathrm{Cu}$ 呈增加趋势; $\mathrm{Pb} 、 \mathrm{Cr} 、 \mathrm{Zn}$ 的变 化可以分为两段, 底部 $-75 \mathrm{~cm}$ 段 $\mathrm{Pb} 、 \mathrm{Cr} 、 \mathrm{Zn}$ 增加, $75-30 \mathrm{~cm}$ 段 $\mathrm{Pb} 、 \mathrm{Cr} 、 \mathrm{Zn}$ 减少.

固城湖沉积物中 $\mathrm{TOC} 、 \mathrm{TN} 、 \mathrm{TP}$ 及 $\mathrm{C} / \mathrm{N}$ 随深 度变化的状况(图 4)说明,TOC、TN 剖面变化可以 分为两段. 底部 $-30 \mathrm{~cm}, \mathrm{TOC} 、 \mathrm{TN}$ 保持稳定. 从 $30 \mathrm{~cm}$ 开始 $\mathrm{TOC} 、 \mathrm{TN}$ 快速增加至 $5 \mathrm{~cm}$ 后下降. TP 变化较为复杂, 底部 $-30 \mathrm{~cm}$ 总体呈减少趋势, 但 波动较大; 30-25 cm 呈现快速下降的特征; $25-30 \mathrm{~cm}$ 比较稳定. TOC/TN 稳定在 11.6 左右, 表层两个样相对 较低, 为 $11.1 、 11.4$. 


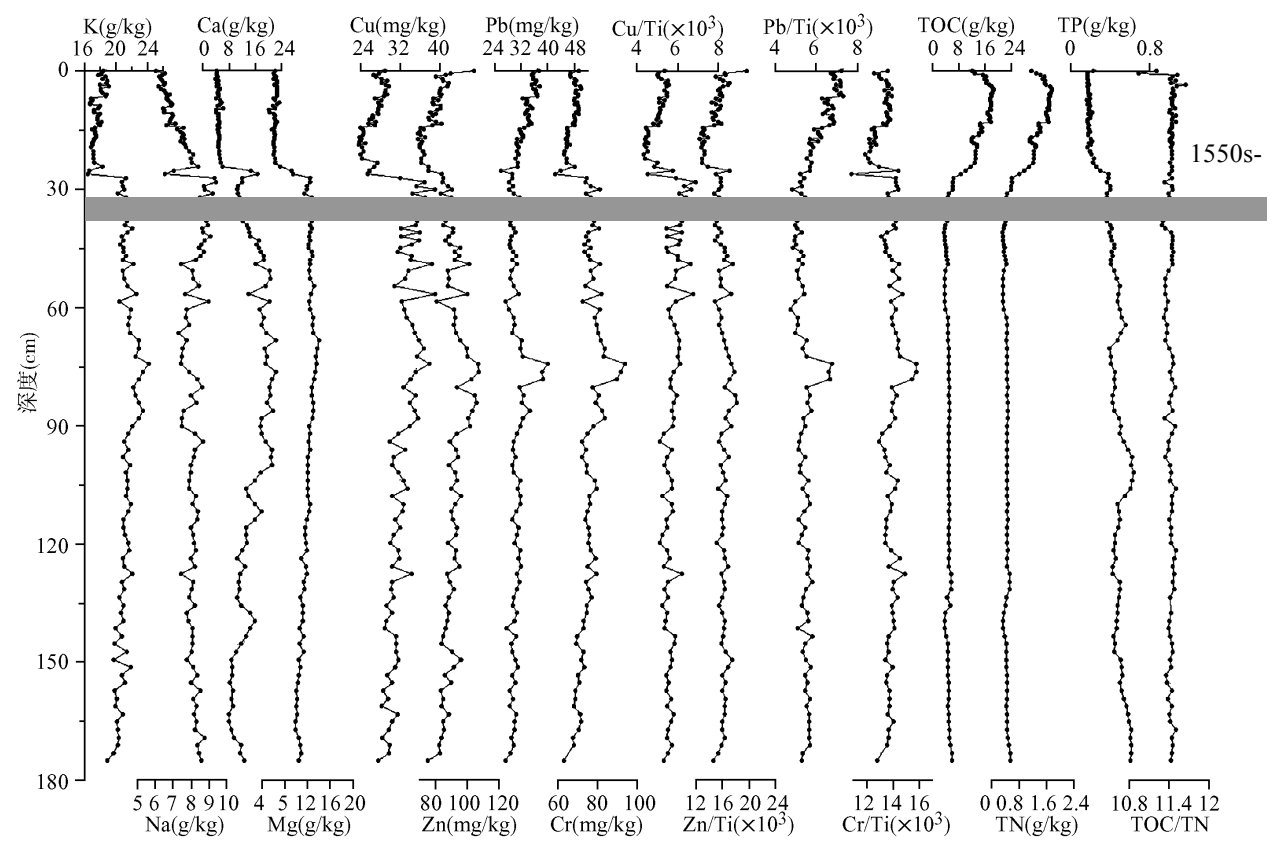

图 4 固城湖 GC-3 孔元素的剖面变化

Fig.4 The vertical profiles of elements in Lake Gucheng GC-3 core

\section{4 讨论}

\section{1 湖泊沉积模式与人类活动}

该湖泊沉积物全部为淤泥，只能选择细颗粒(4-11 $\mu \mathrm{m})$ 物质进行等效剂量测量. 但对固城湖湖心钻孔 岩芯的 ${ }^{14} \mathrm{C}$ 和光释光测年结果表明全样有机质的 ${ }^{14} \mathrm{C}$ 年龄与石英的光释光年龄存在系统差异, 后者较前者 年轻约 2000 年. 说明这些样品的光释光信号在沉积时的晒退程度应该比较彻底, 否则, 残留的光释光信 号将导致光释光年龄值偏大，而不是偏小. 系统光释光的测年研究排除了光释光年龄低估的可能性，二 者的差异可能是湖泊沉积物碳库效应的反映 ${ }^{[12]}$. 若以 $50 \mathrm{~cm}$ 处为 7000 年以来的沉积计算, 得到的沉积速 率仅为约 $0.007 \mathrm{~cm} / \mathrm{a}$, 远低于现代沉积速率. 而根据羊向东等人在围层区钻孔的测年结果，认为缺失了 $6400 \mathrm{BP}$ 以来的沉积 ${ }^{[13]}$. 对比邻近的太湖, 钻孔在 $35 \mathrm{~cm}$ 处孢粉组合发生明显变化, 钻孔上部被认为可能 存在沉积间断 ${ }^{[14-15]}$. 从多环境代用指标来看, 固城湖在 $30 \mathrm{~cm}$ 发生剧变(图 4). 因此很有可能, 在固城湖 存在沉积物缺失.

据研究，固城湖是经由古丹阳湖解体分化而产生的众多子湖中较大的湖泊之一. 固城湖历史发展过 程中, 圩田与胥溪河的关系被认为是密不可分, 胥溪运河的开挖和东坝等堰、闸、坝的兴废直接影响到 固城湖面积的消长 ${ }^{6]}$, 吉磊等人通过钻孔的研究也认为开挖胥溪河后, 湖水位下降, 为大量围怎提供了 可能 ${ }^{[16]}$. 从现代沉积物定年来看, 其平均沉积速率为 $0.066 \mathrm{~cm} / \mathrm{a}$, 外推得到 $30 \mathrm{~cm}$ 代表了约 450 年的沉积, 这与下坝建成的时间一致. 因此, 有可能是在下坝建成之后，由于水面扩大，圩区被淹，湖泊沉积物持续 沉积. 在此之前, 原有的湖泊沉积物很可能是受到人为的扰动或是曾经干涸过, 出现沉积间断. 推测在 $30 \mathrm{~cm}$ 上下两部分沉积物的物源有很大的差异是因为两者对应的流域不一样. 即 $30 \mathrm{~cm}$ 以下部分对应的是 古丹阳湖大湖时期的流域系统，而 $30 \mathrm{~cm}$ 以上部分对应的是固城湖已作为一个独立的湖泊并受到人为围 居影响后的小湖流域系统.

\section{2 近代人类活动的湖泊沉积响应}

${ }^{210} \mathrm{~Pb}$ 的 CRS 法测出固城湖上世纪 60 年代沉积速率是 1920 s 以来最大的，对应了该段时间开始的大 规模围湖层殖活动. 据调查, 解放后在 “以粮为纲” 的方针指导下，不顾湖泊的生态环境条件，盲目围湖 
造田, 使湖泊的面积急剧缩小 ${ }^{[6]} .1960-1980$ 年 20 年间固城湖面积从 $65 \mathrm{~km}^{2}$ 缩小到 $24.5 \mathrm{~km}^{2}$, 被围垦了 $40.5 \mathrm{~km}^{2}$, 而围剭会造成进人湖泊的沉积物增加. 沉积速率的高峰只出现在围垦开始的 60 年代, 可能和围 是刚开始时对地表的大量破坏有关, 而之后修筑堤坝使得进人湖泊的泥沙物质减少, 导致沉积速率减小. 对洪湖现代沉积物的研究亦表明, 上个世纪 50 年以来的围旺活动期间出现了相对较高的沉积速率 ${ }^{[17]}$.

在固城湖沉积剖面中, ${ }^{137} \mathrm{Cs}$ 比活度剖面只出现了一个蓄积峰, 对应切尔诺贝利事件. 而 1963 年的峰 却未出现. 分析固城湖 1963 年峰消失的原因, 可能是带放射性核素的沉积物沉积后再迁移造成的, 即上 世纪 60 年代强烈的人类围旺活动. 前面已经指出, 20 世纪 60 年代初是固城湖受扰动最严重的时期, 其沉 积物沉积速率也最高, 大量沉积物突然进人湖泊, 可能造成 ${ }^{137} \mathrm{Cs}$ 混合迁移, 使得 ${ }^{137} \mathrm{Cs}$ 峰消失.

钻孔底部至 $75 \mathrm{~cm}$ 段, $\mathrm{Pb} 、 \mathrm{Zn} 、 \mathrm{Cr}$ 出现增加的趋势, 对比沉积物年龄看这是至少 7 千年前的沉积物质, 不应存在人为造成的污染. 其原因应可能是湖泊沉积物物质来源发生改变, 使得其成分产生变化. 为区 别自然和人类来源物质的差异, 一个通常的识别方法是采用参考元素, 如 $\mathrm{Ti}{ }^{[18]}$. Ti 在沉积物中的含量与矿 物组成有显著的关联, 且受人为活动影响较小, 其变化受控于自然物质来源的差异. $\mathrm{Cu} 、 \mathrm{~Pb} 、 \mathrm{Zn} 、 \mathrm{Cr}$ 与 $\mathrm{Ti}$ 的比值剖面变化曲线(图 4), 说明底部至 $30 \mathrm{~cm}$ 的 $\mathrm{Cu} 、 \mathrm{~Pb} 、 \mathrm{Zn} 、 \mathrm{Cr}$ 与 $\mathrm{Ti}$ 的含量比值基本保持稳定, 消 除了物质来源差异的影响. 而在钻孔上部 $25 \mathrm{~cm}$ 内, 不仅元素 $\mathrm{Cu} 、 \mathrm{~Pb} 、 \mathrm{Zn} 、 \mathrm{Cr}$ 的含量增加, 其与 $\mathrm{Ti}$ 的比 值也在增加, 因此有可能是人类活动造成的人湖污染物增加造成的.

致谢: 夏威岚高级工程师进行 ${ }^{210} \mathrm{~Pb} 、{ }^{137} \mathrm{Cs}$ 年代测定, 朱育新副研究员进行元素的测定, 隋桂荣老师进行 营养盐的测定，董旭辉博士生、刘恩峰博士也对论文的写作提出了不少宝贵意见，特此感谢!

\section{5 参考文献}

[1] 王苏民, 李建仁. 湖泊沉积——研究历史气候的有效手段: 以青海、岱海为例. 科学通报, 1991, 36(1): 54-56.

[2] 羊向东, 王苏民, 沈 吉等. 近 0.3ka 来龙感湖流域人类活动的湖泊环境响应. 中国科学(D 辑), 2001, 30(12): 1031-1038.

[3] Albuquerque ALS, Mozeto A A. C: N: P ratios and stable carbon isotope compositions as indicators of organic matter sources in a riverine wetland system (Moji-guacu river, Sao Paulo-Brazil). Wetlands, 1997, 17(1): 1-9.

[4] Howarth RW, Fruci JR, Sherman D. Inputs of sediment and carbon to an estuarine ecosystem: influence of land use. Biological Applications, 1991, 1(1): 27-39.

[5] 朱广伟, 陈英旭. 沉积物中有机质的环境行为研究进展. 湖泊科学, 2001, 13(3): 272-279.

[6] 窦鸿身, 汪宪栕. 固城湖的成因与历史演变. 地理文集, 1983, 1(7): 1-9.

[7] 王苏民, 窦鸿身. 中国湖泊志. 北京: 科学出版社, 1998: 293-294.

[8] 姚书春, 王小林, 薛 滨. 全新世以来江苏固城湖沉积模式初探. 第四纪研究, 2007, 27(3): 365-370.

[9] 隋桂荣. 太湖表层沉积物中 OM、TN、TP 的现状与评价. 湖泊科学, 1996, 8(4): 319-324.

[10] 中国科学院南京土壤研究所编. 土壤理化分析. 上海: 上海科学技术出版社, 1978.

[11] 王小林, 姚书春, 薛 滨. 江苏固城湖近代沉积 ${ }^{210} \mathrm{~Pb} 、{ }^{137} \mathrm{Cs}$ 计年及其环境意义. 海洋地质动态, 2007, 23(4): 21-25.

[12] 张家富, 周立平, 薛 滨等. 湖泊沉积物的 ${ }^{14} \mathrm{C}$ 和光释光测年——以固城湖为例. 第四纪研究, 2007, (4): 522-528.

[13] 羊向东, 王苏民, 童国榜. 江苏固城湖区一万多年来的孢粉植物群及古季风气候变迁. 植物学报, 1996, 38(7): 576-581.

[14] Chang WYB. 11000 年以来太湖的形成与演变. 古生物学报, 1996, 35(2): 129-135.

[15] 薛 滨, 翟文川, 吴艳宏等. 太湖晚冰期-全新世气候环境变化的沉积记录. 湖泊科学, 1998, 10(2): 30-36.

[16] 吉 否, 王苏民, 郑长苏等. 浅钻岩芯揭示的固城湖 4000 年来环境演化. 湖泊科学, 1993, 5(4): 316-323.

[17] 姚书春, 薛 滨, 夏威岗. 洪湖历史时期人类活动的湖泊沉积环境响应. 长江流域资源与环境, 2005, 14(4): 475-480.

[18] Mônica ALS, Carlos ER. Behavior of selected micro and trace elements and organic matter in sediments of a freshwater system in south-east Brazil. The Science of the Total Environment, 2002, 292: 121-128. 